\title{
Cervical Sonoelastography and Cervical Length Measurement but not Cervicovaginal Interleukin-6 Are Predictors for Preterm Birth
}

\author{
Autoren \\ A. Weichert ${ }^{1}$, D. von Schöning ${ }^{1}$, T. Fischer ${ }^{2}$, A. Thomas ${ }^{3}$ \\ Institute \\ Department of Obstetrics, Charité-Universitätsmedizin Berlin, Berlin, Germany \\ Department of Radiology and Ultrasound Research Laboratory, Charité-Universitätsmedizin Berlin, Berlin, Germany \\ Department of Obstetrics and Ultrasound Research Laboratory, Charité-Universitätsmedizin Berlin, Berlin, Germany
}

\section{Key words \\ sonoelastography \\ cervical length \\ preterm birth \\ - cervix}

$\begin{array}{ll}\text { received } & 26.06 .2015 \\ \text { revised } & 21.02 .2016 \\ \text { accepted } & 17.05 .2016\end{array}$

Bibliografie

DOI http://dx.doi.org/

10.1055/s-0042-110317

Published online: 2016

Ultrasound International Open

2016; 2: E77-E82

(C) Georg Thieme Verlag KG

Stuttgart · New York

ISSN 2199-7152

\section{Correspondence}

\section{Dr. A. Weichert, MD}

Department of Obstetrics

Charité-Universitätsmedizin Berlin

Campus Charité Mitte

10117, Berlin

Germany

Tel.: +49/30/450664188

Fax: +49/30/4507664188

alexander.weichert@charite.de

\section{unantiom

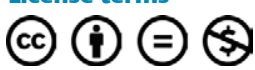

\section{Abstract}

$\nabla$

Purpose: Worldwide, preterm birth annually affects more than 15 million infants. Despite increasing knowledge of the risk factors and mechanisms associated with preterm labor, the preterm birth rate has risen in most industrialized countries. The ability to identify women at high risk for spontaneous preterm birth is crucial yet remains difficult. The aim of the present study was to assess the value of cervical length measurements in combination with sonoelastography and interleukin 6 (IL-6) concentrations in cervicovaginal secretions to identify women at risk for preterm birth.

Materials and Methods: 36 pregnant women with signs of threatened preterm birth were enrolled in our prospective cohort study. Cervical length measurement, sonoelastography, and IL-6 levels from cervicovaginal swab samples were measured.

\section{Introduction}

\section{$\nabla$}

Preterm birth is defined as delivery before a gestational age of 37 weeks. Annually, more than 15 million children are affected worldwide. It is the main cause of perinatal morbidity and mortality, and almost one-half of long-term neurologic morbidity cases and approximately 3-quarters of neonatal mortality are associated with preterm birth [1,2]. Furthermore, approximately one-third of neonatal deaths are caused by prematurity leading to more than 1 million newborn deaths per year [3].

Despite advancing knowledge of the risk factors and mechanisms associated with preterm labor and delivery, the preterm birth rate has risen in most industrialized countries [4]. This increase has been partially attributed to a rise in multiple pregnancies that occurred as a result of assisted
Results: The preterm birth rate was found to be $33.3 \%$ in our study cohort. Maternal age did not differ between the preterm and term birth groups. Measurement of the cervical length alone was found to have a sensitivity of 0.7 and a specificity of 0.8 , whereas cervical sonoelastography had a sensitivity of 0.66 and a specificity of 0.82. By using a combination of both methods, the sensitivity and specificity were found to be 0.9 and 0.7 , respectively. IL-6 levels were not found to differ between women with term deliveries and women with preterm births.

Conclusion: Both, cervical sonoelastography and cervical length measurement are valuable tools in identifying women with threatened preterm birth. The highest correlation with the outcome preterm birth was achieved using a combination of both cervical length measurement and cervical sonoelastography.

reproductive technologies and better outcomes in indicated preterm births [5].

The ability to identify women at high risk for spontaneous preterm birth is crucial yet remains difficult. In women with preterm contractions, $30 \%$ of preterm labors resolve spontaneously, whereas $50 \%$ of women treated for preterm labor deliver at term [6]. In addition to typical risk factors, such as low socioeconomic status, multiple pregnancies, or a history of cervical surgery, the primary methods used for the detection of preterm birth are transvaginal ultrasound and the presence of fetal fibronectin (fFN) in cervicovaginal fluid. These methods allow clinicians to perform targeted interventions such as referral to a tertiary care center, antenatal corticosteroid administration, and tocolysis. The relationship between cervical length and the incidence of preterm birth is well-known [7]. 
Another emerging approach is the detection of biomarkers associated with preterm birth. They can be stratified into different pathways and include extracellular matrix degradation and inflammatory response in intrauterine infection and inflammation. Fetal fibronectin glycoprotein is present in the extracellular matrix and promotes cellular adhesion at fetal-maternal interfaces (uterine-placental and decidual-chorionic). Disruption of these interfaces results in its release into cervicovaginal secretions [8].

Intrauterine infection and inflammation are important precursors of preterm birth [9]. The cytokine interleukin (IL)-6 has both pro- and anti-inflammatory properties. IL-6 is a major mediator of host response to inflammation and infection by activating T- and B-cells, macrophages, and osteoclasts. [10]. Furthermore, it is among the most frequently reported biomarker for spontaneous preterm birth [11]. Concentrations of IL-6 have been reported to be elevated in amniotic fluid, cervical fluid, and cord plasma, particularly in response to intraamniotic inflammation and microbial invasion of the intraamniotic cavity. Preterm births were found in women with visible fetal membranes that had high IL-6 (cut-off: $56 \mathrm{pg} / \mathrm{ml}$ ) levels in cervicovaginal secretions, suggesting that IL-6 may be useful in managing patients with visible membranes and preterm premature rupture of membranes [12].

Sonoelastography is a new sonographic technique that measures soft tissue stiffness. Diagnostic advantages of detecting focal lesions in various tissues such as the breast, liver, and thyroid gland by comparison of the stiffness of the abnormal area to the adjacent normal tissue have been reported in numerous studies [13-15]. Sonoelastography of the uterine cervix has been used to evaluate not only normal findings but also abnormal findings such as cervical cancer or suspicious cytology [15]. In pregnant women, sonoelastography of the cervix has been proposed to be an objective method for assessing tissue softening in the region of the internal os of the cervix prior to the induction of labor [16], although the suggestion that sonoelastographic measurements of tissue displacement may reflect histological changes that may provide a measure of cervical ripening has been implied as being premature [17]. However, both of the aforementioned studies are rather limited, as the analyzed data stemmed from selected areas of the whole elastographic image. Given that penetration depth is a physical limitation of sonoelastography, we evaluated the anterior lip of the cervix as described in previous studies $[15,18]$. From our point of view, sonoelastography is pioneering technology and valuable tool because the results are immediately available.

The aim of the present study was to identify women at risk for preterm birth. Therefore, we analyzed general risk factors for preterm birth. Beyond that we assessed the value of cervical length measurements in combination with sonoelastography and IL-6 concentrations in cervicovaginal secretions.

\section{Materials and Methods}

$\nabla$

\section{Study design, setting, and demographics}

A prospective cohort study was performed on 36 obstetric patients receiving care at the Department of Obstetrics, Charité University Hospital, Berlin, Germany. This study was approved by the institutional ethics committee (EA4/011/12).

Inclusion criteria consisted of: maternal age of 18 years and over; gestational age between $22+0$ and $33+6$ weeks; and sym- ptoms suggestive of threatened preterm birth. Singleton and multiple pregnancies were included in our study. Patients were enrolled in the study if they presented symptoms of threatened preterm labor, such as preterm labor, intermittent lower abdominal pain, or sonographic cervical shortening. Exclusion criteria were as follows: cervical dilation; previous pelvic examination (including transvaginal ultrasound); frank bleeding or placenta previa; prior cervical cerclage; sexual intercourse within the previous $24 \mathrm{~h}$; or rupture of membranes. Informed written consent was obtained from all participants at the time of enrollment. Gestational age was confirmed by early obstetric ultrasound examination.

Demographic data collected from the participants included maternal age, number of previous pregnancies as well as term and preterm deliveries, gestational age at the time of enrollment in the study, body mass index (BMI), and nicotine abuse. Gestational age at the time of delivery was obtained from hospital records.

\section{Detection of interleukin-6}

The concentration of IL- 6 in the cervicovaginal secretions was measured according to the manufacturers' instructions (Milenia Biotec, Gießn, Germany). Following insertion of a sterile speculum, a Dacron swab was placed into the posterior fornix and lightly rotated for $15 \mathrm{~s}$ to allow absorption of the vaginal secretions. The swab was transferred to a test tube containing buffer solution. $100 \mu \mathrm{l}$ from each solution was pipetted to the sampling well of the Picoscan IL-6 cassette. The Picoscan IL-6 cassette is a lateral flow immunoassay. The cassette was placed in an analyzer that measures the color intensity of the test band following incubation for $20 \mathrm{~min}$ at room temperature. The IL-6 concentration $(\mathrm{pg} / \mathrm{ml})$ was calculated according to a stored standard curve.

\section{Sonoelastography}

Ultrasound measurement of the cervix and assessment of cervical funneling were performed using a Premium Ultrasound System (HI VISION Preirus, Hitachi Medical Corporation, Tokyo, Japan) in dorsal lithotomy position with a $4-8 \mathrm{MHz}$ endocavity transducer.

2 experienced obstetric ultrasound specialists (A.W., A.T.) scanned the patients successively within the same session. The reason for this approach was to avoid an additional vaginal examination. Patients were encouraged to empty their bladder prior to the examination. The cervix was visualized in the sagittal plane. The canal length was measured following the recommendations of Burger and colleagues [19] and lams and co-workers [20].

Following measurement of the cervical length, sonoelastography evaluation was performed. During acquisition, no additional pressure was applied. The ultrasound observers were blinded to one another's findings. Tissue displacement and the generated strain were qualitatively shown in a scaled color image superimposed over the conventional B-mode ultrasound image. Blue represents stiff tissue, green is indicative of average stiffness, and red represents soft tissue ( $\bullet$ Fig. 1 ).

In our study, the contrast and threshold were adjusted to refine detail and eliminate noise. A rectangular region of interest (ROI) box was adjusted to encompass the anterior cervical lip and the endocervical canal. The color distribution has been evaluated by a semi-quantitative technique. In detail the available color spectrum included 256 different colors. The measured color pixels in the designated region of interest (ROI) were set in relation to this scale and the results were shown as percentages. 

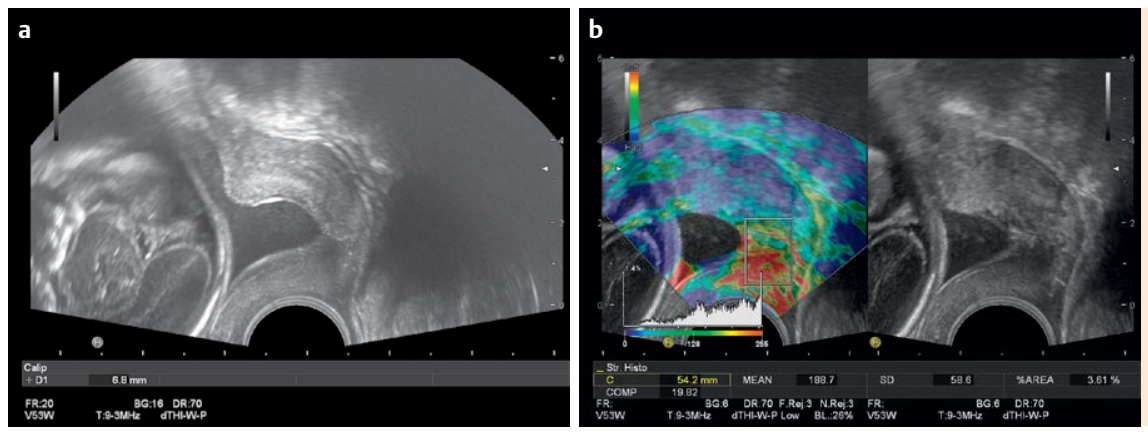

Fig. 1 Transvaginal ultrasound images of a 21-year-old woman (gravida 1, para 0 ) at 23 gestational weeks threatened by preterm birth. a Transvaginal ultrasound image demonstrating a short cervix $(6.8 \mathrm{~mm})$. b Corresponding sonoelastography image with a rectangular region of interest (ROI). The red color in the ROI indicates soft tissue. The color distribution from green to red is shown in the histogram. $3.61 \%$ of the area is blue.

Tab. 1 Characteristics of the study population.

\begin{tabular}{|lc} 
Variable & Mean \pm SD, $(95 \% \mathrm{Cl})$ \\
Maternal age, years & $31.37 \pm 4.73(29.6-33.1)$ \\
\hline Gravidity & $2.03 \pm 2.13(1.2-2.8)$ \\
\hline Parity & $0.40 \pm 0.93(0.1-0.7)$ \\
\hline Gestational age at enrollment, weeks & $29.03 \pm 3.64(27.7-30.4)$
\end{tabular}

The arithmetic mean of the blue stain (stiff tissue) was calculated from 3 measurements and used for further statistical analysis.

\section{Statistical analysis}

Clinical characteristics of the patients were expressed as median (range) and number (percent). The relationship between the various parameters was assessed by means of univariate analysis and logistic regression analysis. In cases where variables were missing from the participants, the evaluated sample size is indicated.

A receiver-operating characteristic (ROC) curve was used to determine the best cut-off values for cervical length, stiff tissue (mean percentage of the blue stain via sonoelastography), and IL-6 concentration for predicting preterm birth. The provided area under the curve (AUC) was a reflection of the diagnostic accuracy, incorporating sensitivity and a false-positive error rate (1-specificity). Data were expressed as mean \pm SE with $95 \% \mathrm{CI}$. The inter-rater reliability of the measurements of the 2 raters was assessed by analysis of the intra-class correlation (ICC).

Statistical analysis was performed using SPSS version 18.0 (SPSS, Chicago, IL) and GraphPad Prism, version 6.0 (GraphPad Software, San Diego, CA, USA).

\section{Results}

\section{Patient characteristics}

36 women with threatened preterm birth were referred to our department and enrolled in the study. One of the patients declined to continue participation in the study, and iatrogenic preterm birth was present in 2 women as a result of maternal preeclampsia and fetal distress. 3 participants were excluded due to the absence of obstetric outcome data. Thus, following the exclusion of the aforementioned participants, the data from 30 pregnant women were further analyzed. Of these pregnancies, $6(20 \%)$ were multiple (twin) gestations. The characteristics of the study participants are presented in 0 Tab. $\mathbf{1}$.

The maternal age at the time of enrollment ranged from 19 to 40 years. In the participants, gravidity ranged from 1 to 10 , and parity ranged from 0 to 4 . The mean gestational age at enrollment was 29 weeks. Gestational age at delivery ranged from 31 to 41 weeks of gestation. 20 patients delivered after $37+0$ gesta- tional weeks (66.6\%), while 10 patients delivered preterm (33.3\%). Maternal age was not observed to differ between the preterm and term groups. The mean age in both groups was 31.4 years at the time of enrollment [preterm, $31.4 \pm 4.72(95 \% \mathrm{CI}$, $28.0-34.8$ ) vs. term $31.4 \pm 4.86$ (95\% CI, 29.1-33.6; $P=0.99$ )]. No significant difference was found between the preterm and term groups in terms of gravidity $(2.20 \pm 2.44$ (95\% CI, 0.5-3.95) vs. $1.95 \pm 2.01(95 \% \mathrm{CI}, 1.0-2.9) ; P=0.92)$ and parity $(0.7 \pm 1.25(95 \%$ $\mathrm{CI},-0.2-1.6)$ vs. $0.25 \pm 0.716(95 \% \mathrm{CI},-0.1-0.6) ; P=0.13)$. However, a significant difference $(P=0.047)$ in gestational age at the time of enrollment was observed between the preterm group [27.1 $\pm 3.90(95 \% \mathrm{CI}, 24.3-29.9)]$ and the term group [30.0 \pm 3.18 (95\% CI, 28.5-31.5)].

\section{General risk factors for preterm birth}

The maternal BMI was available for 21 participants and ranged from 18 to 29.4 at the time of enrollment [24.56 \pm 3.11 (95\% CI, 23.2-26.0)]. A significant difference in BMI $(P=0.047)$ was observed between the participants delivering at term (mean: $23.4 \mathrm{~kg} / \mathrm{m}^{2}$ ) and participants with a preterm delivery (mean: $26.1 \mathrm{~kg} / \mathrm{m}^{2}$ ).

Nicotine abuse was reported in 4 participants (13.2\%), while 24 (80\%) denied smoking during pregnancy. 2 participants refused to answer the question. Smoking was not found to be a significant variable between the 2 groups. 4 patients had a history of preterm birth. We did not observe a significant difference between the term and preterm groups $(P=0.7041)$.

\section{Cervical length measurement, sonoelastography of} the uterine cervix, and IL-6 levels from cervicovaginal secretions as a diagnostic test for preterm birth

The receiver operating characteristic (ROC) curves were generated for cervical length, sonoelastography of the uterine cervix, and IL-6 concentrations ( $\bullet$ Fig. 2 ). The mean cervical length at the time of enrollment was $20.61 \mathrm{~mm}$ (range: $6.4-55 \mathrm{~mm}$ ). In the preterm group, the cervical length was significantly $(P=0.038)$ shorter $[17.8 \pm 14.5 \mathrm{~mm}(95 \% \mathrm{CI}, 7.4--28.2)]$ than that of the term group [22.0 $\pm 8.60 \mathrm{~mm}(95 \% \mathrm{CI}, 18.0-26.0)]$. Data for cervical length measurements were available for all cases, sonoelastography in $87 \%$ and interleukin-6 in $97 \%$, respectively.

The cervical length for each patient was related to the gestational age at delivery. When choosing a cut-off value of $16.35 \mathrm{~mm}$, the sensitivity was $0.85(95 \% \mathrm{CI}, 0.6-1.0)$ and the specificity 0.7 (95\% CI, 0.3-0.9). The area under the ROC curve (AUC) was $0.7350 \pm 0.1137$ ( $95 \% \mathrm{CI}, 0.5-1.0 ; P=0.039$ ).

To assess the risk of preterm birth, we analyzed the median proportion of blue in the ROI box. The proportion of blue was found to be significantly lower (less stiffness) in the preterm group than in the term group ( 4.00 vs. $13.7 ; P=0.0028)$. A cut-off value at 4.568 resulted in a sensitivity of $0.8235(95 \% \mathrm{CI}, 0.6-1.0)$ and 


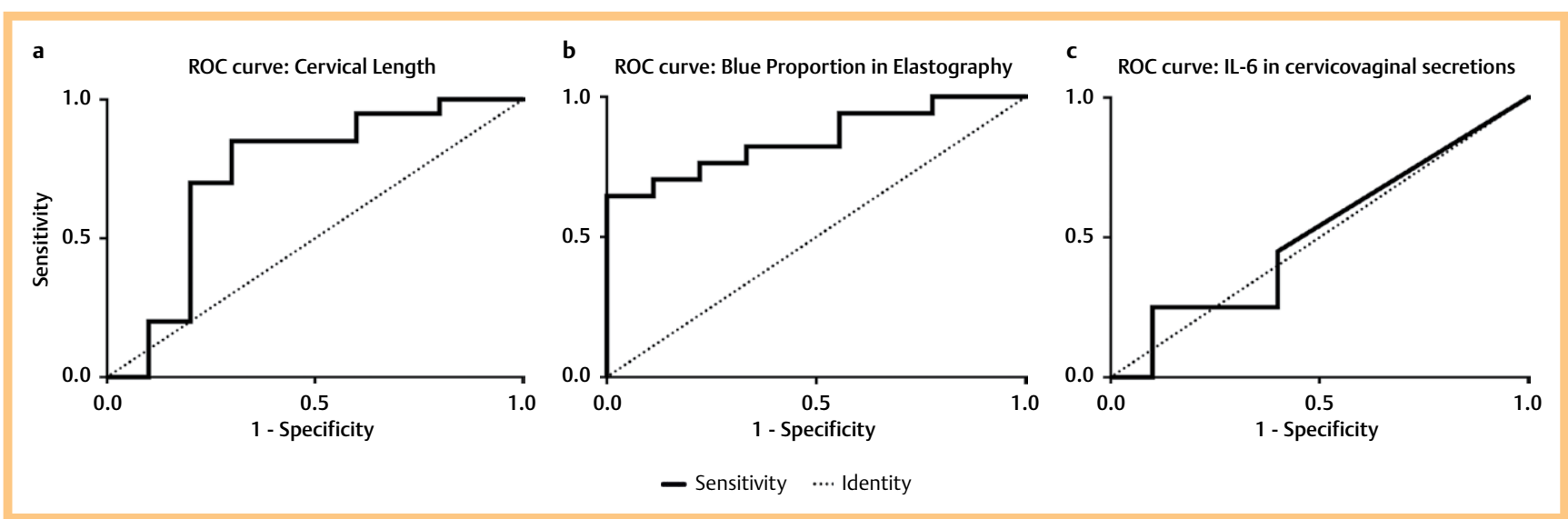

Fig. 2 Receiver operating characteristic curves representing the correlation between gestational age at delivery and cervical length a blue proportion in elastography $\mathbf{b}$, and IL-6 levels in cervicovaginal secretions $\mathbf{c}$.

Tab. 2 ROC curve from cervical length measurements, sonoelastography, and combined methods.

\begin{tabular}{|llll}
\hline & $\begin{array}{l}\text { Cervical } \\
\text { length }{ }^{*}\end{array}$ & $\begin{array}{l}\text { Elastogra- } \\
\text { phy }{ }^{*}\end{array}$ & $\begin{array}{l}\text { Combination of } \\
\text { cervical length } \\
\text { measurement and } \\
\text { sonoelastography }\end{array}$ \\
\hline -value & 0.0277 & 0.0147 & 0.0052 \\
\hline Sensitivity & 0.700 & 0.667 & 0.900 \\
\hline Specificity & 0.800 & 0.824 & 0.700 \\
\hline Positive predictive value & 0.636 & 0.667 & 0.600 \\
\hline Negative predictive value & 0.842 & 0.824 & 0.933 \\
\hline
\end{tabular}

a specificity of $0.6667(95 \% \mathrm{CI}, 0.3-0.9)$. The AUC was $0.8497 \pm 0.074$ ( $95 \% \mathrm{CI}, 0.7-1.0 ; P=0.0039$ ).

The inter-rater reliability of the measurements of the 2 raters was assessed by analysis of the intra-class correlation (ICC). Cronbach's Alpha was 0.996 (95\%CI: 0.990-0.998, p<0.001), indicating a high inter-rater reliability.

In patients with signs of threatened preterm birth, no significant difference in IL-6 concentrations in cervicovaginal secretions was found in patients that went on to have a preterm birth and patients with a term delivery $(P=0.934)$. The mean IL-6 concentration in the preterm group was $154.2 \mathrm{pg} / \mathrm{ml}$ (SD, $269.8 \mathrm{pg} / \mathrm{ml}$; $95 \% \mathrm{CI}, 38.83-347.2)$ and in the term delivery group was $152.4 \mathrm{pg} / \mathrm{ml}$ (SD, 200.9; 95\% CI, 58.4-246.4). The area under the ROC curve was observed to be $0.51 \pm 0.1155$ ( $95 \% \mathrm{CI}, 0.3-0.7$; $P=0.9299$ ).

To predict the risk of preterm birth, we used a combination of the ROC curve results obtained from the cervical length measurements and sonoelastography. The results are summarized in 0 Tab. 2. Both cervical length measurement and cervical sonoelastography produced significant data to assess the risk of preterm birth. Measurement of the cervical length alone had a sensitivity of 0.7 and a specificity of 0.8 , whereas cervical sonoelastography had a sensitivity of 0.66 and a specificity of 0.82 . However, when both of these methods were combined, the sensitivity was found to be 0.9 and the specificity 0.7 .

\section{Discussion}

Preterm birth, defined as delivery before 37 completed gestational weeks, is the most important cause for perinatal mortality and morbidity. Worldwide, approximately 15 million babies are born preterm, and 1 million children die each year due to preterm birth complications [21]. Due to advances in medicine, most newborns affected by preterm birth are more likely to survive nowadays. However, up to $75 \%$ of health issues that occur in childhood such as cerebral palsy, cognitive and speech delays, motor and visual deficits, and learning difficulties, are a result of preterm birth [22]. Therefore, preterm birth is a global problem not only for health care providers and affected families, but also for healthcare systems in general.

Women at risk for preterm birth are usually identified by their obstetrical history, demographic factors, or classic symptoms [23], as it allows the initiation of risk-specific treatment such as tocolysis or administration of antenatal corticosteroids. For example, women that are extremely underweight or overweight are more likely to be at risk for preterm birth $[24,25]$. However, maternal weight can be influenced by various factors such us low socioeconomic status or ethnicity, and is therefore not an independent variable. In our study, women who delivered preterm had a significantly higher BMI compared to women that delivered at term. Interestingly, women from the preterm group were found to be enrolled 3 weeks earlier than the term group. Despite the introduction of several public health interventions such as promoting awareness of preterm birth and centralization of perinatal care, or medical interventions such as prophylactic intrapartum antibiotics, progesterone or cerclage, the preterm birth rate has not decreased significantly over the last decades. In addition to the development of innovative interventions, the most favorable approach for reducing the global incidence of preterm birth lies in the introduction of perinatal care programs in low-income countries due to the high preterm birth rates [26]. The primary problem is the identification of women who actually deliver preterm. This is attributed to a number of diagnostic dilemmas. Preterm contractions are rather inaccurate in identifying women with threatened preterm labor. In addition, a short cervix alone delivers vague results. Approximately $70 \%$ of women with a singleton gestation and a cervical length of $10 \mathrm{~mm}$ have been found to deliver their children at term [27]. The goal of our study was to examine a cohort of patients admitted to our department with signs of threatened preterm birth by 
3 methods in order to assess potential combinations that may improve the identification of women at risk for preterm birth.

The value of cervical length measurements alone to predict preterm birth has been the focus of numerous studies. However, a systematic Cochrane review concluded that there is insufficient evidence to recommend cervical length screening in both asymptomatic and symptomatic women [28]. This highlights the need for additional tests. Fetal fibronectin (fFN) is the most evaluated biochemical marker used to predict preterm delivery. Women with a cervical length above $30 \mathrm{~mm}$, or between 15 and $30 \mathrm{~mm}$ in combination with a negative fFN test, have been found to have a risk of less than $5 \%$ for spontaneous preterm delivery within 7 days after testing [29]. In our study, the cervical length was found to be significantly shorter in women affected by preterm birth than in term deliveries $(17.8 \mathrm{~mm}$ vs. $22.0 \mathrm{~mm}$, respectively). The sensitivity and specificity to predict preterm birth were $70 \%$ and $80 \%$, respectively.

Biochemical markers and cytokines for the prediction of preterm birth have been the subject of previous studies, given that the inflammatory response plays a major role in preterm birth [30]. There have been contradictory results concerning IL-6 levels as an indicator of preterm birth. IL-6 concentrations in cervicovaginal secretions have been observed to be significantly higher in women with preterm birth and in women with visible fetal membranes compared with women with a closed external os [12]. In addition, high levels of IL-6 have been reported in cervicovaginal fluid which was found to have a reverse correlation with the cervical length [31]. In contrast, higher cytokine concentrations, such as IL-6, IL-1b and IL-8, were found in all study participants, including controls, in a study by Chandiramani and colleagues, who concluded that these cytokines play a minimal role in cervical shortening [32]. The findings of our study are in accordance with these findings. The AUC was $0.51 \pm 0.1155$. No significant difference was observed between women that had a preterm delivery compared with women that delivered at term. The uterine closure mechanism was evaluated in the standard way by digital palpation. Nowadays, sonoelastography is used to visualize tissue stiffness and elasticity by superimposing a colorcoded image, which is similar to color Doppler imaging. Cervical sonoelastography has been widely employed to evaluate cervical lesions [15] and preterm birth [18], or prior to the induction of labor [16]. However, while some authors have reported advantageous findings [33], others have found contradictory results [34]. Other authors even concluded that it is too early to use elastographic tissue displacement as a reflection of histological changes in cervical ripening [17].
This is mainly owed to physics such as the limited penetration depth of sonoelastography. For instance, if there is amniotic fluid in the cervix - regardless of the cause, short cervix or funneling - the posterior lip cannot be evaluated. Physically this is caused by the absence of compressibility in water, which leads to inhomogeneous pressure distribution. Therefore, we chose to measure the tissue stiffness in the anterior cervical lip and internal os. Our method was described in previous studies of our group $[15,18]$.

We investigated a moment not a time interval. Therefore, intra-rater reliability is not available. However, the inter-rater reliability was high (Alpha $=0.996)$.

In our cohort, sonoelastography performed comparably to cervical length measurement, with a sensitivity and specificity of $66.7 \%$ and $82.4 \%$, respectively. However, in combination with cervical length measurement, the sensitivity was found to be 0.9 with a specificity of 0.7 .

In light of recent studies and the availability of other technologies that aid in detecting women at risk for preterm birth such as fetal fibronectin, we propose a step-wise diagnostic approach to evaluate both sonography and sonoelastography, in addition to biochemical aspects, in the identification of women at risk for preterm birth ( $\bullet$ Fig. 3 ). If a patient with signs of preterm birth is referred, cervical length measurement in combination with cervical sonoelastography should be performed. In patients with "soft" cervices identified by sonoelastography, fFN should be carried out. Following identification of a "soft" cervix and positive fFN results, the patient should be admitted to the hospital. We recommend that all other cases be monitored with regular outpatient checkups.

By implementing these criteria, the rate of unnecessary hospital admission can be reduced with a consequent significant decrease in expenses. Furthermore, exposure to potential side effects of tocolytic drugs, as well as corticosteroids, may possibly be reduced for low-risk patients.

Our study had several limitations. First, the study was comprised of a relatively small number of participants. Approximately $20 \%$ of participants were excluded from further analysis. Second, there was a selection bias in the cohort, and our clinic is a tertiary care referral center specialized in high-risk obstetrics and neonatology. "Late preterms", born between 34 and 36 weeks + 6 days of gestation, account for approximately $80 \%$ of all preterm births and $8 \%$ of total births [35]. This cohort is underrepresented in our study. All of the enrolled patients were referred to our department prior to 30 gestational weeks. This may be explained by the fact that several nearby hospitals accept pregnant

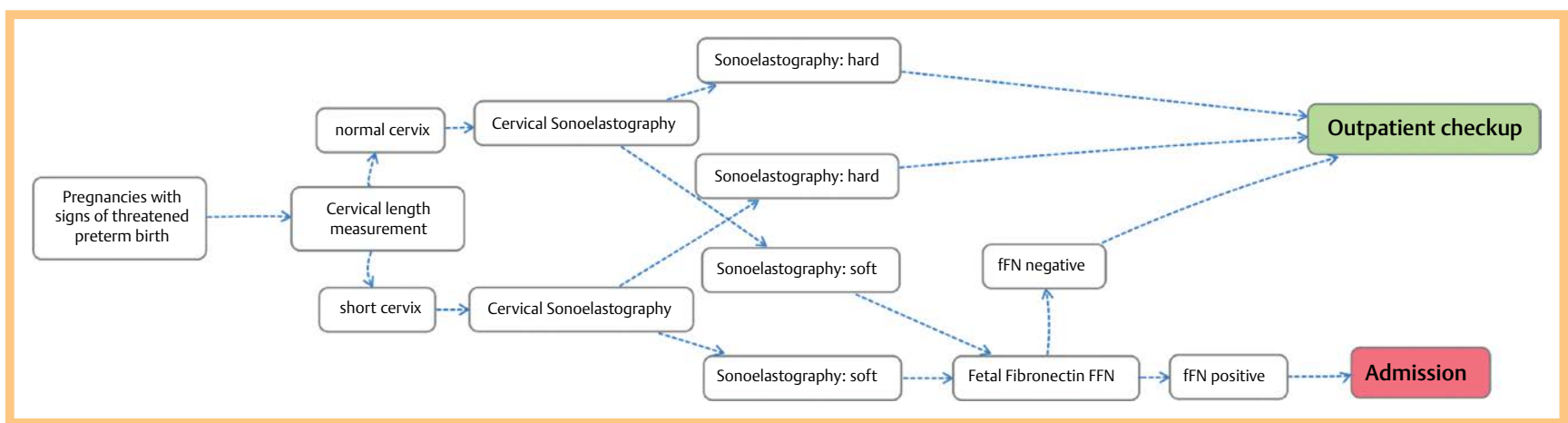

Fig. 3 Proposed clinical algorithm to identify women at a high risk for preterm birth using a step-wise approach. Step I shows the conventional cervical length measurement, followed by sonoelastography (step II). In women affected by a "soft cervix", additional fetal fibronectin testing is recommended (step III). 
women from 32 weeks of gestation and onwards, as upon birth, these infants are considered "functionally mature".

Finally, IL-6 and elastography measurements were not consistently available for all participants.

This study confirms and expands on previous observations suggesting that cervical sonoelastography in combination with cervical length measurement might be a valuable tool in identifying women threatened by preterm birth. Cervical length measurement and sonoelastography were found to predict preterm birth, while IL- 6 concentrations from cervicovaginal secretions did not significantly differ between the preterm and term groups. The combination of cervical length measurement and cervical sonoelastography resulted in a high correlation with the outcome preterm birth.

The results of our study are in accordance with our clinical experience and support our proposal of the implementation of a combination of markers for the identification of women at risk for preterm birth. An improvement in detection rates may be achieved by the addition of biochemical markers such as fFN. Further evaluation in larger longitudinal studies is required to confirm these preliminary results.

\section{References}

1 McCormick MC. The contribution of low birth weight to infant mortality and childhood morbidity. N Engl J Med 1985; 312: 82-90

2 Saigal S, Doyle LW. An overview of mortality and sequelae of preterm birth from infancy to adulthood. Lancet 2008; 371: 261-269

3 Lawn JE, Gravett MG, Nunes TM, Rubens CE, Stanton C. Global report on preterm birth and stillbirth ( 1 of 7 ): definitions, description of the burden and opportunities to improve data. BMC Pregnancy Childbirth 2010; 10 (Suppl 1): S1

4 Blencowe H, Cousens S, Oestergaard MZ, Chou D, Moller A-B, Narwal $R$ et al. National, regional, and worldwide estimates of preterm birth rates in the year 2010 with time trends since 1990 for selected countries: a systematic analysis and implications. The Lancet 2012; 379: 2162-2172

5 McClamrock HD, Jones HW Jr, Adashi EY. Ovarian stimulation and intrauterine insemination at the quarter centennial: implications for the multiple births epidemic. Fertil Steril. 2012; 97: 802-809

6 King JF, Grant A, Keirse MJ, Chalmers I. Beta-mimetics in preterm labour: an overview of the randomized controlled trials. Br J Obstet Gynaecol. 1988; 95: 211-222

7 To MS, Fonseca EB, Molina FS, Cacho AM, Nicolaides KH. Maternal characteristics and cervical length in the prediction of spontaneous early preterm delivery in twins. Am J Obstet Gynecol 2006; 194: 1360-1365

8 Feinberg RF, Kliman HJ, Lockwood CJ. Is oncofetal fibronectin a trophoblast glue for human implantation? Am J Pathol 1991; 138: 537-543

9 Goldenberg RL, Hauth JC, Andrews WW. Intrauterine infection and preterm delivery. N Engl J Med 2000; 342: 1500-1507

10 Akira S, Taga T, Kishimoto T. Interleukin-6 in biology and medicine. Adv Immunol 1993; 54: 1-78

11 Menon R, Torloni MR, Voltolini C, Torricelli M, Merialdi M, Betran AP et al. Biomarkers of spontaneous preterm birth: an overview of the literature in the last four decades. Reprod Sci 2011; 18: 1046-1070

12 Vousden N, Chandiramani M, Seed P, Shennan A. Interleukin- 6 bedside testing in women at high risk of preterm birth. J Matern Fetal Neonatal Med 2011; 24: 1301-1304

13 Chong Y, Shin JH, Ko ES, Han BK. Ultrasonographic elastography of thyroid nodules: is adding strain ratio to colour mapping better? Clin Radiol 2013; 68: 1241-1246

14 Ferraioli G, Parekh P, Levitov AB, Filice C. Shear wave elastography for evaluation of liver fibrosis. J Ultrasound Med 2014; 33: 197-203

15 Thomas A, Kummel S, Gemeinhardt O, Fischer T. Real-time sonoelastography of the cervix: tissue elasticity of the normal and abnormal cervix. Acad Radiol 2007; 14: 193-200
16 Swiatkowska-Freund M, Preis K. Elastography of the uterine cervix: implications for success of induction of labor. Ultrasound Obstet Gynecol 2011; 38: 52-56

17 Molina FS, Gomez LF, Florido J, Padilla MC, Nicolaides KH. Quantification of cervical elastography: a reproducibility study. Ultrasound Obstet Gynecol 2012; 39: 685-689

18 von Schoning $D$, Fischer $T$, von Tucher E, Slowinski T, Weichert A, Henrich $W$ et al. Cervical sonoelastography for improving prediction of preterm birth compared with cervical length measurement and fetal fibronectin test. J Perinat Med 2015; 43: 531-536

19 Burger M, Weber-Rossler T, Willmann M. Measurement of the pregnant cervix by transvaginal sonography: an interobserver study and new standards to improve the interobserver variability. Ultrasound Obstet Gynecol 1997; 9: 188-193

20 Iams JD. Cervical ultrasonography. Ultrasound Obstet Gynecol 1997; 10: $156-160$

21 Blencowe $H$, Cousens S, Chou D, Oestergaard M, Say L, Moller AB et al. Born too soon: the global epidemiology of 15 million preterm births. Reprod Health 2013; 10 (Suppl 1): S2

22 Kerr-Wilson CO, Mackay DF, Smith GC, Pell JP. Meta-analysis of the association between preterm delivery and intelligence. J Public Health (Oxf) 2012; 34: 209-216

23 Lockwood CJ, Dudenhausen JW. New approaches to the prediction of preterm delivery. J Perinat Med 1993; 21: 441-452

24 Han Z, Mulla S, Beyene J, Liao G, McDonald SD.Knowledge Synthesis G. Maternal underweight and the risk of preterm birth and low birth weight: a systematic review and meta-analyses. Int J Epidemiol 2011; 40: $65-101$

25 McDonald SD, Han Z, Mulla S, Beyene J.Knowledge Synthesis G. Overweight and obesity in mothers and risk of preterm birth and low birth weight infants: systematic review and meta-analyses. BMJ 2010; 341: c3428

26 Chang HH, Larson J, Blencowe H, Spong CY, Howson CP, Cairns-Smith $S$ et al. Preventing preterm births: analysis of trends and potential reductions with interventions in 39 countries with very high human development index. Lancet 2013; 381: 223-234

27 Iams JD, Goldenberg RL, Meis PJ, Mercer BM, Moawad A, Das A et al. The length of the cervix and the risk of spontaneous premature delivery. National Institute of Child Health and Human Development Maternal Fetal Medicine Unit Network. N Engl J Med 1996; 334: 567-572

28 Berghella $V$, Baxter $J K$, Hendrix NW. Cervical assessment by ultrasound for preventing preterm delivery. Cochrane Database Syst Rev 2013; 1: CD007235

29 van Baaren GJ, Vis JY, Wilms FF, Oudijk MA, Kwee A, Porath MM et al. Predictive value of cervical length measurement and fibronectin testing in threatened preterm labor. Obstet Gynecol 2014; 123: $1185-1192$

30 Goldenberg RL, Culhane JF, Iams JD, Romero R. Epidemiology and causes of preterm birth. Lancet 2008; 371: 75-84

31 Hadzi-Lega M, Markova AD, Stefanovic M, Tanturovski M. Correlation of cervical length, fetal fibronectin, phIGFBP-1, and cytokines in spontaneous preterm birth up to 14 days from sampling. J Perinat Med 2014

32 Chandiramani M, Seed PT, Orsi NM, Ekbote UV, Bennett PR, Shennan $A H$ et al. Limited relationship between cervico-vaginal fluid cytokine profiles and cervical shortening in women at high risk of spontaneous preterm birth. PLoS One 2012; 7: e52412

33 Hee L, Rasmussen CK, Schlutter JM, Sandager P, Uldbjerg N. Quantitative sonoelastography of the uterine cervix prior to induction of labor as a predictor of cervical dilation time. Acta Obstet Gynecol Scand 2014; 93: 684-690

34 Pereira S, Frick AP, Poon LC, Zamprakou A, Nicolaides KH. Successful induction of labor: prediction by preinduction cervical length, angle of progression and cervical elastography. Ultrasound Obstet Gynecol 2014; 44: 468-475

35 Davidoff MJ, Dias T, Damus K, Russell R, Bettegowda VR, Dolan $S$ et al. Changes in the gestational age distribution among U.S. singleton births: impact on rates of late preterm birth, 1992 to 2002. Semin Perinatol 2006; 30: 8-15 